\title{
HONEYCOMB LUNGS WITH PERICHOLANGITIS
}

\author{
BY \\ S. SIVANESAN \\ From the Department of Pathology, University of Malaya, Singapore
}

(RECEIVED FOR PUBLICATION APRIL 3, 1959)

Cystic lungs are diverse both morphologically and aetiologically. One form of cystic lungs characterized by multiple air-containing thin-walled cysts, having a maximum diameter of $1 \mathrm{~cm}$., scattered more or less uniformly throughout both lungs, was described by Fowler and Godlee (1898) as 'honeycomb' or 'worm-eaten' in appearance.

Honeycomb lungs have been found only in association with other disorders (Heppleston, 1956). These may take the form of granulomata such as eosinophilic granuloma, tuberose sclerosis (Oswald and Parkinson, 1949), tuberculosis, sarcoidosis (Heppleston, 1956) and pericholangitis or allied hepatic disorders.

This disease occurred especially in children (Sharkey, 1894; Tooth, 1897; Fletcher, 1901; Bernstein, 1905). Were it not for the confusing terminology in the literature, such as foetal bronchiectasis (Sandoz, 1907), congenital bronchiectasis, congenital cyst formation of lung (Koontz, 1925), alveolar cystic disease and cystic emphysema (Willis and Almeyda, 1943; Paliard, Plauchu, Galy and Papillon, 1946), this condition might well have been reported more often under the name of honeycomb lungs.

A case of honeycomb lungs with pericholangitis is presented here.

\section{Case History}

A 2-year-old Chinese boy was admitted to the paediatric unit of the General Hospital, Singapore, with dyspnoea, cough, sweating and fits. He was apparently well till the evening before the day of admission, when the parents noticed difficulty in breathing, a slight cough and sweating. At noon on the day of admission the child began to have fits.

He was the seventh child of normal parents, the siblings being normal and well. Birth was normal, the patient then weighing $7 \frac{1}{2} \mathrm{lb}$. Mental and physical growth were normal.

On examination the patient was having fits. The eyes were rolling upwards and there was frothing at the mouth. He had a temperature of $103^{\circ} \mathrm{F}$. and had generally been very toxic with dyspnoea and cyanosis. The throat was injected, and the tongue dry and coated. The trachea was central, respiratory rhythm was normal and on auscultation harsh breath sounds were heard. The pulse rate was 130 per minute, and no abnormality was detected in the cardiovascular system. The liver was three fingerbreadths palpable below the right costal margin. The spleen and lymph nodes were not palpable. There were no abnormalities detectable in the central nervous system or skeletal system. The child died within one hour of admission.

Autopsy. The body was that of a cyanosed, undernourished Chinese boy. There were no external deformities.

The trachea and bronchi contained a fair amount of frothy fluid. Both lungs were fully expanded. There were no pleural adhesions nor exudate. The surface of both lungs was studded with numerous cysts varying from $0.1 \mathrm{~cm}$. or less to $1.0 \mathrm{~cm}$. (Fig. 1). The larger

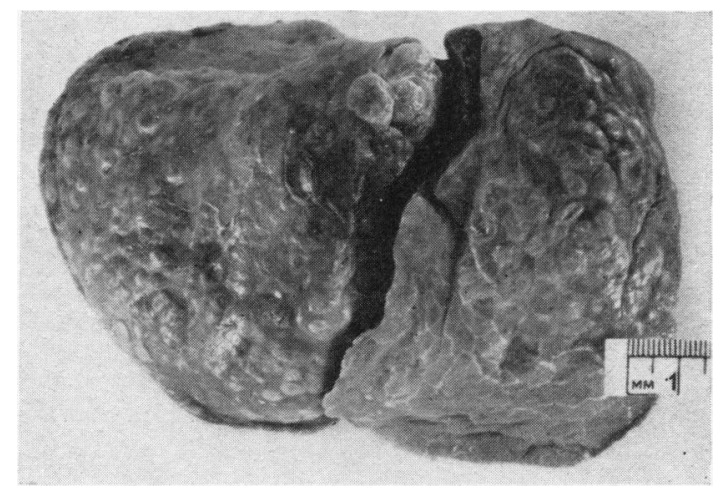

Fig. 1.-P.M. 2034/58. Shows the surface of the right lung studded with numerous cysts.

cysts had thin transparent walls and were raised above the general surface of the lungs while others were within the substance of the lungs. A group of confluent cysts was conspicuous at the apical segment of the right lower lobe. Cysts were also seen in both lungs on all aspects of the visceral pleura. The right interlobular fissure dividing the apex and mid-lobe was deficient and represented by a fibrous septum.

The cut surface showed the lungs to be studded with cysts scattered diffusely throughout and extending from 


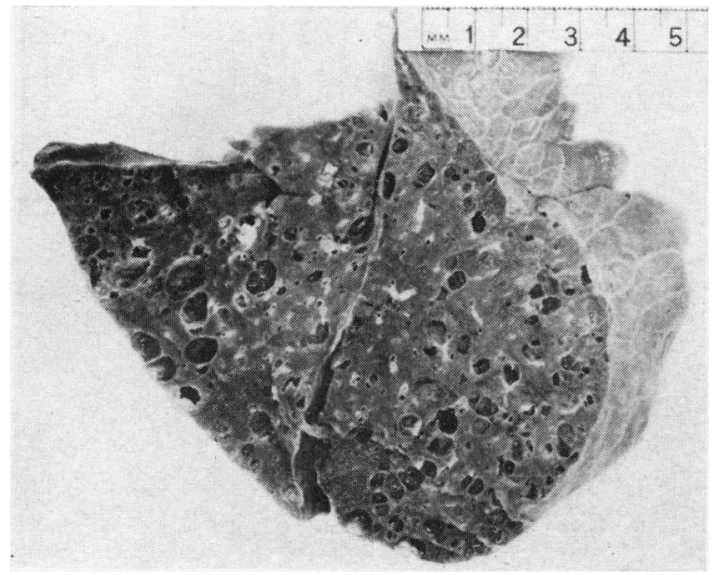

FIG. 2.-P.M. 2034/58. Cut surface of the left lung studded with diffusely scattered cysts.

the hilum to the periphery (Fig. 2), giving them a honeycomb appearance. The cysts varied in size and shape. Most of the cysts had a rounded outline whereas others were polygonal and irregular. They contained air and had a smooth lining. Numerous thin-walled septa protruded into most of the cysts. Some of these septa had pores in them. Some of the cysts were also seen to communicate with other large or smaller ones. The intervening lung tissue was relatively airless and had a fleshy homogeneous appearance.

The liver was enlarged, weighing $570 \mathrm{~g}$. It was firm, had a smooth surface and sharp borders. It was cut with difficulty. The cut surface showed that there were islands of inspissated bile in dilated bile ducts surrounded by a thick dense rim of fibrous tissue (Fig. 3). The intervening parenchyma was apparently normal.

The gall bladder and biliary passages were normal. The pancreas appeared normal. No cysts were seen.

The Peyer's patches were conspicuous, but mesenteric nodes were not enlarged. There was one ascaris worm in the small intestine. The brain was congested. The heart appeared normal in size. There was an oval $(5 \times 3 \mathrm{~mm}$.) auricular septal defect. The valves were

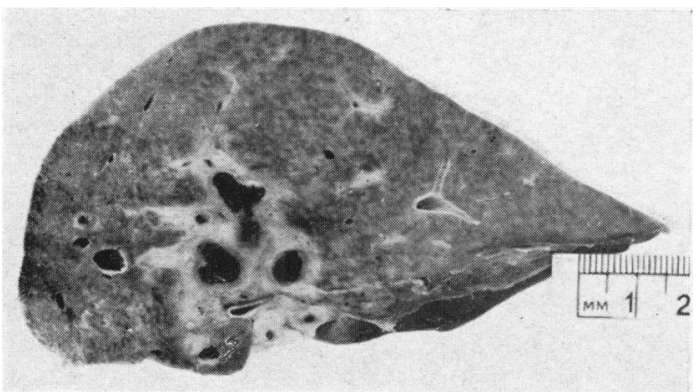

FIG. 3.-P.M. 2034/58. Cut surface of the liver showing islands of inspissated bile surrounded by a thick dense rim of fibrous and granulomatous tissue.

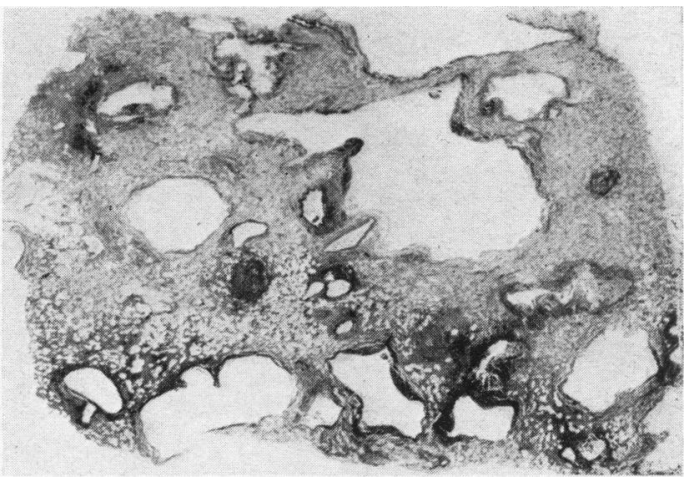

FIG. 4.-P.M. 2034/58. Photomicrograph of cysts and granulomatous tissue. H. and E. $\times 8$.

normal. The spleen, stomach and kidneys appeared normal.

Microscopic Appearances. The only organs to show variations from normal were the lung and liver.

In the lung the most striking features were cysts and granulomatous tissue (Fig. 4). The cysts were of varying size and shape. Larger cysts had a fairly rounded outline and did not communicate freely with other cysts. Smaller cysts had irregular outlines and communicated freely with one another. Thick septal projections were found in some of the cysts. The cysts had no constant lining. Some cysts were partly or wholly lined with granulomatous tissue, others by compressed alveoli and, rarely, flattened epithelium (Fig. 5). No cyst was found to have a complete lining of epithelium.

The distribution of cysts was in close relation to bronchioles and blood vessels (Fig. 6). These included all orders of bronchioles. The larger bronchioles remained discrete, surrounded by several larger and smaller cysts, whilst smaller bronchioles were compressed by the

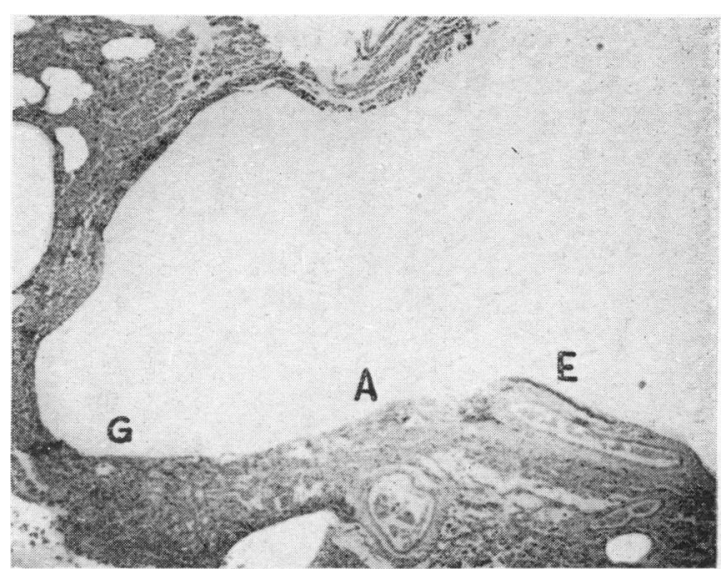

FIG. 5.-P.M. 2034/58. Part of a cyst lined by compressed alveoli (A), granulomatous tissue $(G)$ and epithelium (E). H. and E. $\times 26$. 


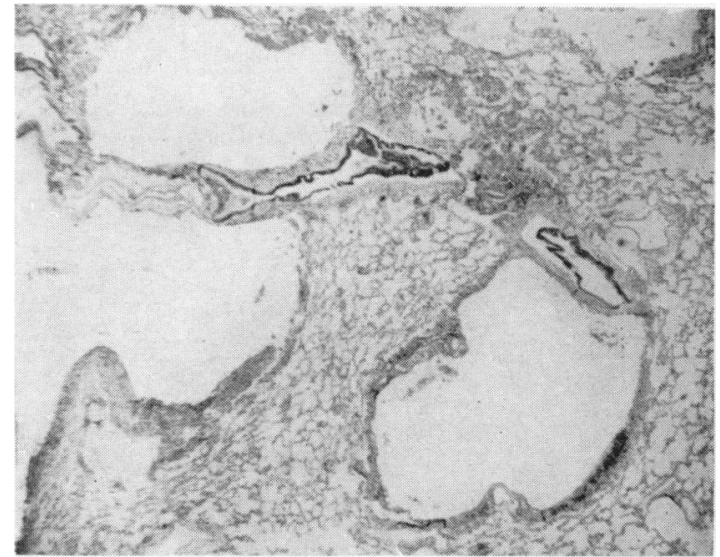

Fig. 6.-P.M. 2034/58. Shows the distribution of cysts to be in close relation to bronchioles and blood vessels $H$. and E. $\times 25$.

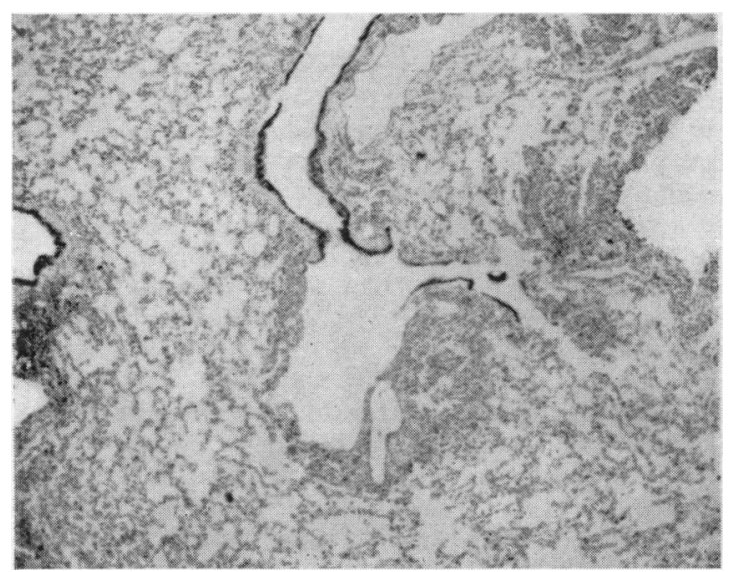

FIG. 7.-P.M. 2034/58. Bronchiole communicating with cyst with bronchiolar epithelium continuing to line part of it. H. and E. $\times 35$.

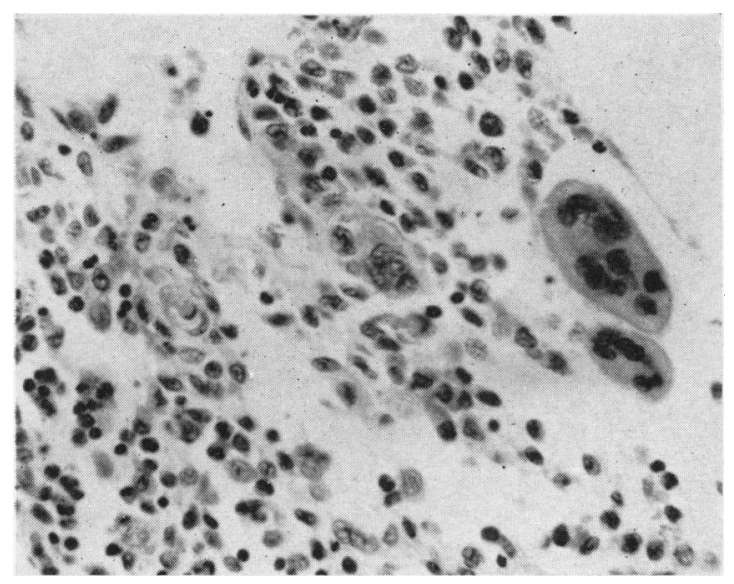

FIG. 8.-P.M. 2034/58. Granulomatous tissue consisting mainly of histiocytes, occasional eosinophils and giant cells. H. and E. $\times \mathbf{4 0 0}$.

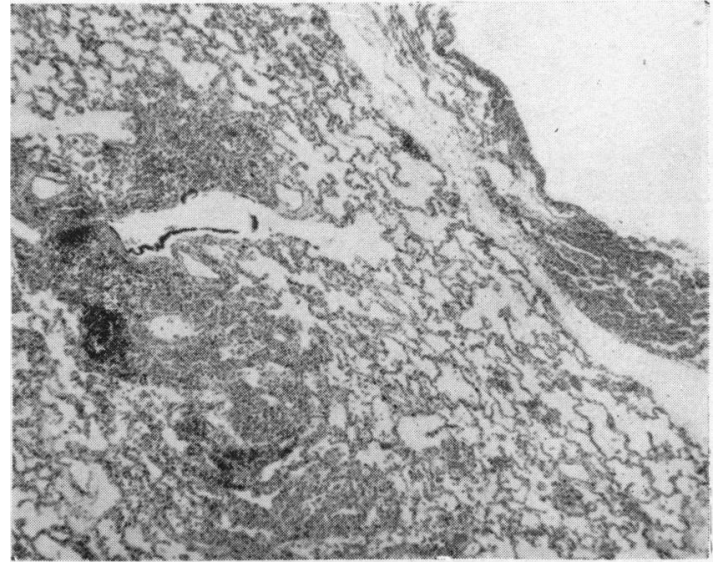

Fig. 9.-P.M. 2034/58. Granulomatous foci in relation to cyst and bronchiole. H. and E. $\times 35$.

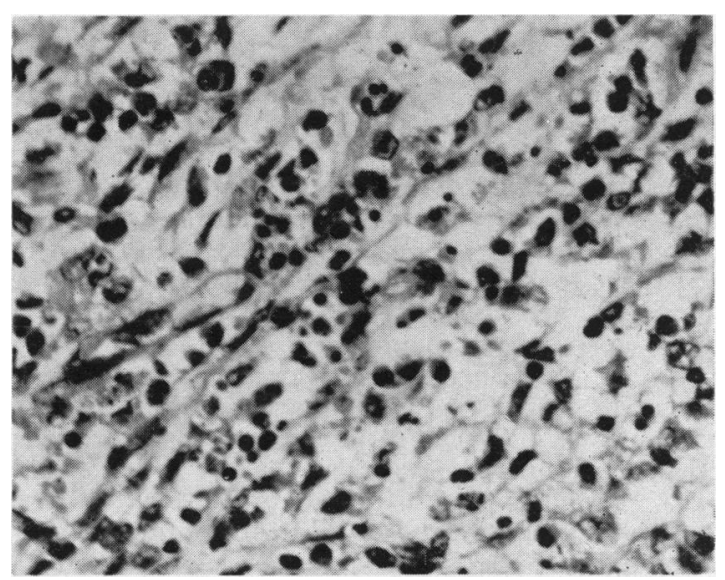

FIG. 10.-P.M. 2034/58. Granulomatous tissue consisting of histiocytes and eosinophils found in relation to bile ducts. H. and E. $\times 400$.

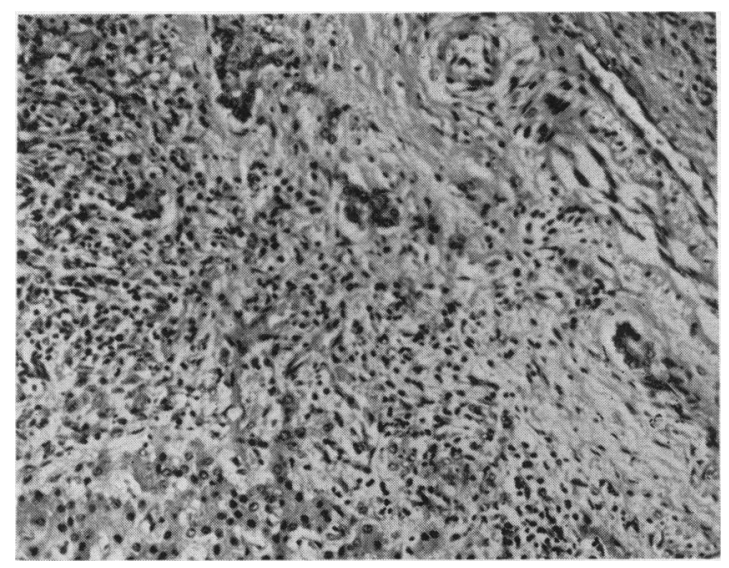

FIG. 11.-P.M. 2034/58. Shows reduplicated bile ducts surrounded by fibious and granulomatous tissue at the margins of liver lobules. $H$. and $E . \times 118$. 
cysts. Serial sections showed communication between cysts and respiratory bronchioles. Where such communication existed the bronchiolar epithelium continued to line part of the cyst (Fig. 7).

The interstitial tissue in cystic areas showed accumulations of granulomatous tissue. Granulomata, consisting mainly of histiocytes, occasional eosinophils and giant cells (Fig. 8), were found to exist as discrete rounded foci in close relation to cysts and bronchioles sometimes abutting on them (Fig. 9). Granulomatous tissue also formed part or whole of the lining of the cysts.

Non-cystic areas of lung showed normal alveolar tissue. A few patches of early bronchopneumonia were seen. There was no abnormal fibrosis or increase in smooth muscle as shown by Van Gieson and picro-Mallory stains.

The bile ducts contained inspissated bile and were found to be dilated. They were surrounded by a thick rim of granulomatous and fibrous tissue. In some parts these were replaced by scar tissue. There was proliferation of bile ducts in the portal tracts. Granulomatous tissue, consisting mainly of histiocytes and a few eosinophils (Fig. 10), was either found as scattered islands in the fibrous tissue or surrounding some of the bile ducts. The liver parenchyma was unaffected except at the margins of the portal tracts where fibrous tissue and reduplicated bile ducts were found infiltrating margins of the lobules (Fig. 11).

\section{Discussion}

The association of honeycomb lungs with pericholangitis is rare. The only other cases in the literature were reported by Fletcher (1901), Bernstein (1905) and Oswald and Parkinson (1949).

The first case reported was a boy, aged $3 \frac{1}{2}$ years. Two weeks before admission there was abdominal pain which was followed by breathlessness and cough. On examination the respiratory rate was increased; there were râles and rhonchi over both lungs. The liver was enlarged. He died with extreme dyspnoea five days after admission. At post-mortem examination the lungs had a honeycomb appearance, and the liver was enlarged (weight $600 \mathrm{~g}$.) with cystic dilatation of the bile ducts.

The second case was a girl, aged 3 years, admitted to Westminster Hospital with a history of pain in the back and cough for one month. She was cyanosed, febrile and severely breathless, and she died very soon after admission. Necropsy revealed a right-sided pneumothorax and both lungs had a honeycomb system of cavities throughout. The liver was enlarged (500 g.) and on section yellow nodules the size of a pin's head were seen. Microscopy of the liver showed small round and oval cells surrounding the bile ducts.

The third case in the series was a boy, aged 2 years, admitted with severe dyspnoea, cough and cyanosis. He had clubbing of the fingers, and the percussion note over the chest was hyper-resonant. Rhonchi were present throughout the lungs. During the next two weeks his condition deteriorated and he died from progressive heart failure. At post-mortem examination diffuse cystic changes were found throughout the lungs. The liver was studded with pale nodules. On microscopic examination the cysts were irregular in size and contained varying degrees of epithelial lining, and the liver showed widespread, subacute and chronic inflammation of the mucosa of the large bile ducts with concentric fibrosis. The inflammatory cells were mostly mononuclear.

Earlier discussions on the nature of honeycomb lungs stressed a congenital cause for this condition. This explains terminology such as foetal bronchiectasis, congenital cyst formation of lung, congenital cyst malformation of lung, congenital bronchiectasis and honeycomb lungs, which were all used synonymously (Koontz, 1925). Some of the views put forward to support a congenital basis were faulty development of alveoli from the small end bulbs of the bronchial tree in the embryo (Sandoz, 1907), aplasia of the alveoli (Hueter, 1914) and foetal atelectasis (Adami and Nicholls, 1911).

These explanations suggest that the negative intrapleural pressure, which at birth would cause normal alveoli to expand, exerts its pull on the bronchioles in these cases, leading to the so-called foetal bronchiectasis. It is interesting to note that a congenital heart defect, such as was found in the case described above, is a factor contributing to foetal atelectasis (Sutherland, 1913). To meet the criteria for a congenital origin the cysts should be more than mere distensions of alveoli, such as those found in emphysema. In the case presented, cysts with a partial epithelial lining continuous with that of respiratory bronchioles were seen. This and the fact that cysts were found close to and surrounding the bronchioles suggest a congenital defect of respiratory bronchioles and proximal portions of alveolar ducts which predispose them to cyst formation.

It is becoming increasingly evident that honeycomb lung is a manifestation of many disorders. Heppleston (1956) regards pulmonary fibrosis or granulomata as the usual antecedents of honeycomb lungs. Cunningham and Parkinson (1950) studied in detail nine cases of honeycomb lungs and came to the conclusion that six of these showed varying degrees of a granulomatous process resulting in fibrosis.

In the case described here there was granulomatous tissue consisting predominantly of histiocytes and a few eosinophils in the lungs and the liver. Fibrosis was seen only in the liver. This granulomatous tissue is the result of an inflammatory reaction which may be due to allergy, a chronic infection or even ascariasis. 
Cyst formation in the lungs probably resulted from stenosis caused by granulomatous foci abutting on bronchioles and thereby preventing egress of air. Destruction of areas of normal lung by the granulomatous process may lead to distension of the adjacent unaffected alveoli.

Marked periportal fibrosis has been seen in schistosomiasis and to a lesser degree in cases of chronic biliary obstruction. Liver involvement with honeycomb lungs has been reported in eosinophilic granuloma (Rowland, 1928; Farber, 1942; Oswald and Parkinson, 1949). In the present case there were no foam cells and staining of frozen section with Sudan black did not reveal abnormal lipoid content. The histological evidence here suggests that either cholangiectasis with stagnation of bile caused reactionary changes in the portal tracts or that the bile ducts were affected by an inflammatory process with consequent weakening of their walls.

\section{Summary}

A case of honeycomb lungs associated with liver lesions is presented.

In this case and in the three cases previously reported the disease occurred in children between
2 and $3 \frac{1}{2}$ years of age, with an onset of dyspnoea, cough, bizarre findings in the lungs on auscultation and enlarged liver. At autopsy both lungs showed honeycombing and there was an enlarged liver with pericholangitis.

The nature of the lesion is discussed. It is concluded that in the pathogenesis both congenital and acquired factors are involved.

I wish to thank Professor R. Kirk for his kind encouragement, Dr. K. Shanmugaratnam and Dr. C. S. Muir for their valuable criticisms and Mr. V. Nalpon for the photomicrographs.

\section{REFERENCES}

Adami, J. G. and Nicholls, A. G. (1911). In The Principles of Pathology, 2nd ed., Vol. 2. H. Frowde, London.

Bernstein, J. M. (1905). Trans. path. Soc. Lond., 56, 330.

Cunningham, G. J. and Parkinson, T. (1950). Thorax, 5, 43.

Farber, S. (1942). New Engl. J. Med., 226, 394.

Fletcher, H. M. (1901). Trans. path. Soc. Lond., 52, 193.

Fowler, J. K. and Godlee, R. J. (1898). The Diseases of the Lung,

p. 143. Longmans, Green, London.
Heppleston, A. G. (1956). Thorax, 11, 77.

Heppleston, A. G. (1956). Thorax, 11, 77. 520

Hueter, C. (1914). Beitr. path. Anat., 59, 520.

Oswald, N. and Parkinson, T. (1949). Quart. J. Med., 18, 1

Paliard, Plauchu, Galy and Papillon, (1946). Poumon, 2, 205.

Rowland, R. S. (1928). Arch. intern. Med., 42, 611.

Sandoz, E. (1907). Beitr. path. Anat., 41, 495.

Sharkey, S. J. (1894). St. Thom. Hosp. Rep., 22, 33.

Sutherland, G. A. (1913). In Diseases of Children, ed. by A. E. Garrod, F. E. Batten and H. Thursfield, p. 340. Arnold, London.

Tooth, H. H. (1897). Trans. path. Soc. Lond., 48, 30.

Willis, F. E. S. and Almeyda, J. (1943). Tubercle (Lond.), 24, 27. 